\title{
BAVEL: ASPECTO E ESCRITURA EM ULYSSES
}

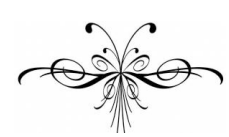

PIERo EyBen
Resumo: Este ensaio propõe-se analisar a linguagem dos monólogos de Ulysses como um pensamento de rastros que, como tal, deve ser lido dentro de um processo tradutório que vise deslocar-se frente às aporias discursivas impostas às atribuições de valor de autoridade (e autoria) e de apropriação (e tradução). Ao perceber que a representação em Joyce apresenta-se como questionamento à própria noção de mímesis - e, com isso, dos modos miméticos como compreendidos por Platão e Aristóteles -, o presente trabalho tem por objetivo entender os vãos e as impossibilidades do discurso no texto e na tradução.

Palavras-Chave: Monólogo, Rastro, Tradução, Desconstrução, Joyce

\begin{abstract}
The proposal of this essay is to examine the language of the monologues in Ulysses as a thought of traces which, as such, must be read within a translation process that aims to move forward to the discursive aporias imposed on the value of authority (and authorship) and ownership (and translation). Realizing that Joyce's representation is presented as questioning the very notion of mimesis - and, therefore, the mimetics modes as understood by Plato and Aristotle -, the present paper aims to understand the gaps and the impossibilities of speech in the text and in the translation.
\end{abstract}

Keywords: Monologue, Trace, Translation, Deconstruction, Joyce 
She dare not bear the sunnygolden babe of day. [Ela não ousa suportar o aurálacre bebê do dia.]

\section{pergunta inicial quando falamos à Joyce, à maneira de Joyce, poderia ser: o que é ler depois do acontecimento Joyce? Em que termos a estrutura textual pode ser pensa-} da? Há um texto que se dispõe em um novo tempo. Joyce escreve-nos sobre um tempo novo. Desse modo, tudo o que faz Ulysses é manter-nos sob uma espécie de jogo, de artimanha do jogo - da impossível tradução de play - que preenche de alusões toda selvageria dos sentidos e das maquinações. Assim, o sentido, e o método de sua busca, é um ritrovai per una selva oscura, um lançar-se pelas modalidades da escritura, pelos tropos e pelos topos. A língua suposta - recriada apenas para uma obra, como o grego homérico - é um ato, maquínico, de afirmação, que "ouvre l'espace d'une re-marque" (DERRIDA, 1987, p. 59). Sendo isso, toda leitura, às portas do altare diaboli, como parodiará o narrador durante a obra, é um ato único do dizer, um fazer que é dizer, já pela menção e pela missão. Todo um sistema de envios é necessário para fazer desses heróis comuns espécimes remarcados, reassinados de seu espaço, de sua marca citadina. Nesse sentido, Dublin é uma forma não apenas de deambular, mas sobretudo de fazer deambular a linguagem - "the flow of the language it is" (JOYCE, 2000a, p. 192) -, como Shakespeare, por similar sounds. O dizer de Joyce é um dizer do tempo que separa, claramente, dois tempos, duplo caminhar: o tempo da consciência e o tempo da inconsciência.

Assim, talvez nunca Mallarmé estivesse tão completamente correto em sua ira frente aos leitores indigestos dos jornais, dos leitores da pressa, pelos jornais. A necessidade de uma leitura na brisure, na prática disseminada apresenta uma possibilidade de realinhamento da interpretação para "devant l'agression, rétorquer que des contemporains ne savent pas lire" (MALLARMÉ, 2003, p. 234). Porque nossos coetâneos não sabem ler é que não se pode - ou melhor, encontram-se temeridades na leitura de Ulysses - construir uma tradição teórica à Joyce. A inauguração da ingenuidade - como também propõe o mestre de Valvins - está na linguagem literária de uma "flower of corruption" (JOYCE, 2000, p. 239), de uma piada sobre si mesmo, que faz das falas dos personagens sua própria assinatura. Como Hamlet, o silêncio ("But break, my heart; for I must hold my tongue") é ainda a melhor forma de devolver ao monólogo sua interioridade in-existencial. A necessária corrupção dos sentidos - a flor de todos e nenhum buquê - seria talvez a melhor saída para conduzir nossos olhos afirmativamente (eyes e Yes, ou ainda, I Yes). 
Ulysses representa uma espécie de pilhagem discursiva na qual toda sua textualidade é fundada por um jogo de esconder dos sujeitos que se enunciam. Não há autoridade mantida pela voz narrativa e, nesse sentido, o querer-dizer do texto é apenas um emaranhado de distâncias percorridas pelo tempo, variando-se. Há, no entanto, esse jogo de modulações do interno - inside, inner - que se projetam como técnica da insistência do inconsciente das personagens pelo tempo que se faz e refaz na memória desse 16 de junho. O tom dessa interioridade está na marca daquele sim repetido, desnaturalizado, paródico (no sentido mais forte de 'canto paralelo'). É de se ouvir, pela estrutura pós-flaubertiana do style indirect libre, a reiteração de uma consciência que se dissolve pelas consonâncias de linguagem que se marcam pela ausência, e por seus agenciamentos. Dito de outro modo, aquilo que Stephen, Leopold e Molly não dizem, mas pensam/desejam (e desejam frente à multiplicidade interminável de seus remetimentos), é a marca de um tempo lógico diferente e muito mais estendido do que as marcas naturalistas da história do romance. Ouçam, sem dúvida, os dizeres dos Blooms durante seus monólogos. Eis que há uma ruptura na qual toda representação deve ser descartada e, ao mesmo tempo, repensada em uma nova lógica. Essa quebra com a presentificação da realidade desagradou a percepção de Erich Auerbach. Em Mímesis, diz o teórico, que obras (e seu exemplo é o Ulysses) as quais "empregam o processo múltiplo da reflexão da consciência” (1998, p. 496):

dão ao leitor uma sensação de desesperança; apresenta-se frequentemente algo de confuso ou de velado, algo que é inimigo da realidade que representam; não raramente, uma alienação da vontade prática de viver, ou o gosto na representação das suas formas mais cruas; hostilidade à cultura, expressa com os meios estilísticos mais sutis que a cultura criou por vezes, um encarniçado e radical afã de destruição. (AUERBACH, 1998, p. 496)

A decadência da representação da realidade é transfigurada em termos negativos (desesperança, confusão, alienação). Essa inimizade apontada por Auerbach é, de todo modo, um questionamento dos meios representativos, ou ainda, e dito de outra maneira, é a colocação em causa da estrutura da própria mímesis como a entende Aristóteles. A destruição do aparato representativo, da própria ideia de literatura como "prosa do mundo" e ordenamento das coisas (como se referirá Foucault), se vale dos mecanismos de compreensão apontados pelo estagirita como partes constitutivas da estrutura mimética da poesia. A mímesis aristotélica apresenta a subdivisão entre modos (platônicos), meios (lexis e melopeia) e objetos (personagens em ação, sendo compostos pelo mythos, ethos e dianoia) da representação. O que faz Joyce é produzir uma refração da forma de conceber o elemento a ser representado - o objeto na teoria poética de Aristóteles - por um deslocamento dos modos (a voz é silenciada e lançada no universo velado da mente) e dos meios (em que não importa apenas o 
contar da história, mas sua melopéia evanescente). Há aqui, por certo, um desejo de assassinar que constitui toda a dinâmica do mal-estar representacional. Quanto mais interna e sutil é a voz, mais aquele afã de multiplicidade de elementos representáveis se demonstra como possíveis. Assim, Ulysses representa a crueza de um estágio fundador na cultura literária moderna que, em amplo aspecto, visa colocar a narrativa em renúncia por meio do parricídio daquele ordenamento necessário à compreensão da palavra como sistematizadora da natureza, como elemento meramente contíguo à lógica do mundo.

Joyce contraria a noção simples de unidade representativa por um agenciamento múltiplo, por aquilo que Deleuze e Guattari chamaram de ligne de fuite, que desorganiza a lógica representativa. Ora, a multiplicidade é uma duração para além da propriedade do próprio, ou seja, apresenta-se como desequilíbrio necessário à perda do território representativo da identidade por uma falta que se estabelece como feixes e rastros da diferença. Não há, com isso, em Joyce uma manutenção dos meios e modos da cultura, mas uma reavaliação de seus agenciamentos através dos abalos na própria matéria narrada, no objeto da representação que se volta, narcisicamente, para si mesmo. Ulysses é a desmistificação do livro - é um livro não-livro - uma vez que se dispõe para fora da ideia de raiz e fundamento justamente no ponto em que se aproveita de uma multiplicidade de fontes que rasuram quaisquer possibilidades de origem certa. Deleuze e Guattari, em Milles Plateaux, apontam o princípio de multiplicidade, na construção do "conceito" de rizoma como "c'est seulement quand le multiple est effectivement traité comme substantif, multiplicité, qu'il n'a plus aucun rapport avec l'Un comme sujet ou comme objet, comme réalité naturelle ou spirituelle, comme image et monde" (DELEUZE; GUATTARI, 1980, p. 14). Desse modo, o alargamento agencial das conexões e das consistências apresenta-se como linhas de fuga da matéria narrável, da linguagem que se presta não mais à representação, mas aos deslocamentos e rupturas com o código. Nesse sentido, a noção de rizoma poderia substituir aquela de mímesis? A noção de tradução, àquela de autoridade monológica?

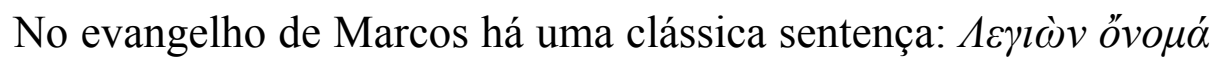

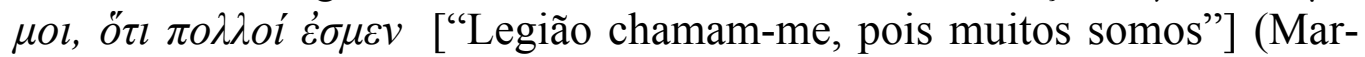
cos, 5: 9). A multidão na consonância dos espíritos forma a marca do inimigo (romano) que se dirige ao personagem de Jesus. Essa legião é marca e rastro de certa forma do habitar humano. Enquanto desloca-se na referência, o sujeito assujeita-se à construção discursiva que o estrutura. Dito de outro modo, o eu, a quem chamam em sua forma dativa, é deslocado para essa falange de multiplicidades; em diversas linhas de fuga, a fala endaimoniada transcorre-se de referente a referente e cria sua morada em uma temporalidade que faz significar a habitação da linguagem. A impostura do uno é imprecisa na compreensão do discurso do monólogo, uma vez que todo sentido edifica-se no rastreamento de ruínas lançado à mes- 
ma palavra reiterada, reabitada. Dessa forma - e todo tradutor deve deterse nesse aspecto - a voz, a modulação da voz, é marca da vivência e da experiência com a linguagem que produz uma demora sobre si, sobre o que está habitando nessa conjuntura.

A representação em Joyce não é mera interioridade refletida, mas se trata de uma obliquidade necessária - é sempre um a mim da referência -, de uma demanda pela experiência interior. Georges Bataille apontou a necessidade de viver a experiência, com nudez e fusão entre objeto e corpo. A busca por um não-saber, para além das faculdades da inteligência, faz passar o limite pelo interno, por aquilo que esse a mim converge em um silenciamento da linguagem. O que se pode traduzir daí, eis o complicador: a experiência interior "ne peut être une sèche traduction verbale, exécutable en ordre" (BATAILLE, 2009, p. 18). O lapso representativo em Joyce está não apenas em uma linguagem desenvolvida pela novidade e invenção, pela impossibilidade de repetição do programa, mas está sobretudo na aporia frente à tradução desse processo de modulação e aspecto, na distribuição de seus remetimentos de rastros que mais surgem em silêncios da linguagem - da linguagem sempre estrangeira e plural, sempre hospedeira e impositiva de sua legalidade - para, longe de valores ou autoridades, estar experimentando, a distância como morada, o interior. Há, portanto, se há necessidade de tradução, a necessidade de comunidade. Uma comunhão de silenciamentos, de diferimentos que impõem a questão: onde o extremo entre objeto e sujeito? Há como traduzir isso? Há traição disso.

A experiência tradutória - essa a possibilidade de ler Joyce, em outro tempo - é o extremo do dizer imposto ao leitor, como marca (remarca) de uma ausência, de um silêncio comunicável como troca. Bataille, ao compreender a experiência interior como necessário elo, necessário apagamento da ilusão de "ser isolado, redobrado sobre si-mesmo" (2009, p. 100), escreve: "l'expérience ne peut être communiquée si des liens de silence, d'effacement, de distance, ne changent pas ceux qu'elle met en jeu" (2009, p. 42). Retornamos ao jogo, àquilo que não pode ser alterado mesmo nos elos da experiência interior. A linguagem participa disso e isso deve ou pode ser traduzido, ou melhor, o pronunciável é um fazer surgir que nunca declina a possibilidade de pulsão para o outro, posto em elos, posto como diferença. A mesmidade, nesse sentido, não participa dessa experiência, não se faz experiência, uma vez que se representa apenas como nome do mesmo, como circunstância de similaridade. Na distância do outro é que o encobrimento da linguagem pode remeter-se infinitamente a uma experiência com o silêncio da modulação da voz, ou seja, apenas na compreensão de seu foco narrativo como diálogo é que se faz emergir a experiência como interior, como imanência do não-sabido, do não-representável.

Entretanto, há, sempre, em Joyce, um eu que fala e cala, que faz da memória seu pensar - faz monumento, faz-se, germanicamente, Denk- 
mal. A complexidade que define o eu, a partir do ponto de vista freudiano, sistematiza-se como um conjunto representável que o sujeito faz de si mesmo, necessário para a constituição do narcisismo. Portanto, pode-se intentar compreender esse eu como uma espécie de Eu narcísico; de eu auto-erotizado ou de investimentos libidinais sobre objetos externos. Esse memorial que constitui o eu que pensa e narra-se em Joyce é, por certo, um processo como o narcisismo freudiano, justamente se o compreendermos como jogo entre o eu e o outro. Freud distinguiu, em Zur Einführung des Narzißmus, o ideal do eu e o eu ideal:

Y sobre este yo ideal recae ahora el amor de sí mismo de que en la infancia gozó el yo real. El narcisismo aparece desplazado a este nuevo yo ideal que, como el infantil, se encuentra en posesión de todas las perfecciones valiosas. Aquí, como siempre ocurre en el ámbito de la libido, el hombre se ha mostrado incapaz de renunciar a la satisfacción de que gozó una vez. No quiere privarse de la perfección narcisista de su infancia, y si no pudo mantenerla por estornárselo las admoniciones que recibió en la época de su desarrollo y por el despertar de su juicio propio, procura recobrarla en la nueva forma del ideal del yo. Lo que él proyecta frente a sí como su ideal es el sustituto del narcisismo perdido de su infancia, en la que él fue su propio ideal. (FREUD, 2007, p. 91)

$\mathrm{O}$ eu, além disso, é construído por processos enunciativos, que podem ser judicativos ou idealizantes. Por um lado, o eu ideal (correspondente ao narcisismo primário) modela o discurso como idealizado, como perfeição de si, para si mesmo; de outro, o ideal do eu faz-se como inscrição no externo ao sujeito, na simbolização. O Narciso joyciano é também o Narciso do tradutor que erotiza um objeto externo com fins de sublimação, de dispêndio do eu para um objeto e desse para a ideia de um eu. O texto joyciano coloca o leitor no lugar impulsivo dessa fragmentação, dessa tentativa de construção do idêntico, por meio da falta, do lugar inencontrável da perfeição. Desse modo, todo o texto é auto-investido, introvertido por uma palavra que não cessa de despir-se em experiência interior, em ultrapassamento do limite do pensável, do representável. Essa armadilha é não menos que o monólogo, que faz ressurgir, à distância, aquilo que perdido e não mutável, aquilo que no remetimento pode ser recuperado, como suplemento, como écart: ruína de um ideal.

Assim, todo sim continua reverberando uma espera pela letra supostamente dita. Há uma demora de esse dizer que se interpela, se produz como versão do dia, no momento noturno de sua mobilidade. Ouço dizer, mas também ouso dizer aquilo mesmo que se encontra performado na impossibilidade de uma palavra familiar. A impossibilidade, no fundo, de uma família, por mais que se insista em uma possível filiação espiritual entre Stephen e Bloom produz na verdade uma não-família operando nos textos de Joyce. A fronteira da casa (Heim) que oculta, que põe às escondidas (Heimlich) o inquietante, o estranho (Unheimlich) impõe-nos uma 
espécie de ruptura dessa morada que é a memória monologada. Apenas rastros se dão a ler, diferenças que se consubstanciam pela desconfiança de "aquacities of thought and language" (2000a, p. 785) - como irrompe Stephen contra a limpeza na água fluente do penúltimo episódio. De seu lar, domiciliando-se à entrada, o estranho permanece como força da habitação. A língua é seu exílio e o caminho não está evidentemente traçado. Assim é terrivelmente estranha a surpresa familiar da proximidade. Rudy e Stephen são decerto o impossível da recusa familiar. A imediata perenidade da ausência do presente, pelo anseio de uma palavra desejante; no inapreensível, no incessante e na dispersão. Maurice Blanchot propõe:

o inteiramente próximo que destrói toda a proximidade, temos, para designá-lo, uma palavra diante da qual nos encontramos de novo, o imediato: o imediato que não permite nenhuma mediação, a ausência de separação que é ausência de relação e também a separação infinita, porque ela nos propicia a distância e o futuro necessários para que pudéssemos nos relacionar, chegar até ele. (BLANCHOT, 2001, p. 89)

Nesse imediato toda presença se dissolve uma vez que seu apagamento está estipulado pela temporalidade do presente. O agora discursivo da literatura - da conversa interminável - permite essa supressão por conduzir sua materialidade nas veredas da espacialidade. Dito de outro modo, aquilo que se diz permanece como dizer e não é a presença do enunciado que fará com que a ausência reiterativa da enunciação se marque como presença mediada pela letra, pelo som. Todo dizer possibilita um a mais no dito, um dito que se reitera infinitamente não pela mediação, mas pela recusa do transitório. O tempo da escritura é o ouvir-dizer que do exterior produz certa vertigem de toda temporalidade. Pensar o imediato pelo "inteiramente próximo" é colocar a perda de mediação como estranho de nós mesmos, implicação de uma resposta impossível ao ato de nomeação. Ora, o monólogo é um dos atos de relacionar-se que se constrói na distância tão abertamente íntima da palavra proferida. A violência escondida da linguagem, de Blanchot, toma forma na obra de Joyce justamente por seu princípio afirmativo dessa ausência, desse épos da inconsciência. Marcar-se pela proximidade é, em amplo espectro, não permitir uma separação entre o sujeito do inconsciente e o sujeito da consciência e nisso os personagens de Ulysses estão muito à frente das possíveis teorias de tempo e linguagem no inconsciente. A recusa ao familiar é, dessa forma, uma tentativa de romper-se na não mediação, na proximidade do si consigo mesmo e com o outro, que ouve o sim do monólogo.

O que ouso dizer faz do dito uma afirmação: há uma fala de individualidades. Um autós controverso que é dissolução e érgon. É um envio a sempre um tu - hamletiano agenbite of inwit [remorso da consciência] que não necessariamente se responde. Os monólogos de Ulysses são, em ampla escala, uma recondução da memória da antiga Musa no sentido de 
trazê-la a um presente que floresce (to bloom) como coro de vozes, mas ao mesmo tempo posto em uma incapacidade de apreender-se nesse coro. A distância, segura, do épos é trocada por um inner - um imo - sem o instrumento vocálico, com a técnica de uma subvocalização que faz do tempo uma cadência sem mediação, uma ausência necessária à percepção da distância da palavra: o que floresce aqui é antes certa prisão em sua própria monódica. Ler a palavra - logos - nos "limites do diáfano", como propõe o incipit do monólogo de Stephen:

Ineluctable modality of the visible: at least that if no more, thought through my eyes. Signatures of all things I am here to read, seaspawn and seawrack, the nearing tide, that rusty boot. Snotgreen, bluesilver, rust: coloured signs. Limits of the diaphane. But he adds: in bodies. Then he was aware of them bodies before of them coloured. How? By knocking his sconce against them, sure. Go easy. Bald he was and a millionaire, maestro di color che sanno. Limit of the diaphane in. Why in? Diaphane, adiaphane. If you can put your five fingers through it it is a gate, if not a door. Shut your eyes and see. (JOYCE, 2000a, p. 45) ${ }^{1}$

Muitas vezes Ulysses, e todo o discurso que dali advém, comporta-se muito mais como um gesto - um jogo de vontades que assumem o discurso da inconsciência - do que uma fala do querer-dizer. Desse modo, o narrador joyciano, sobretudo quando se prepara para o monólogo interior, proporciona uma leitura do que pode escapar "à pura intenção espiri-

${ }^{1}$ As duas traduções brasileiras publicadas apresentam divergências importantes na concepção do texto joyciano. Ambas, como toda atividade tradutória, compreendem e interpretam o texto de forma própria. A tradução mais recente, de Bernardina S. Pinheiro (que grafarei BSP) é mais coloquial e procura manter esse aspecto presente na língua (no texto) de saída. A de Antonio Houaiss (grafado, a partir de agora, por $\mathrm{AH}$ ) vai em busca de uma poeticidade maior em termos de jogos de palavras, mesmo que por isso prejudique o aspecto mais "acessível" do texto. Optei por apresentar as duas traduções, sempre que necessárias, para que o leitor se decida, frente ao texto de saída. E, ainda, por entender que, mesmo com a tarefa hercúlea e bela de dispor-se a essa empreita, nenhum dos dois ateve-se ao problema da modalização e do aspecto. Assim, seguem as traduções:

[BSP: "Inelutável modalidade do visível: ao menos isso se não mais, pensei através dos meus olhos. Assinatura de todas as coisas que estou aqui para ler, ovas-do-mar e destroços-do-mar, a maré se aproximando, a bota enferrujada. Verdemeleca, azulprata, ferrugem: sinais coloridos. Limites do diáfano. Mas ele acrescenta: em corpos. Então ele tinha consciência deles corpos antes de ter deles coloridos. Como? Batendo com a sua cachola neles, lógico. Vá devagar. Calvo ele era e um milionário, maestro di color che sanno. Limite do diáfano em. Por que em? diáfano, adiáfano. Se a gente pode pôr os cinco dedos através dele é um portão, se não uma porta. Feche os olhos e veja." (2005, p. 44)]

[AH: "Inelutável modalidade do visível: pelo menos isso, se não mais, pensado através dos meus olhos. Assinaturas de todas as coisas estou aqui para ler, marissémen e maribodelha, a maré montante, estas botinas carcomidas. Verdemuco, azulargênteo, carcoma: signos coloridos. Limites do diáfano. Mas ele acrescenta: nos corpos. Então ele se compenetrava deles corpos antes deles coloridos. Como? Batendo com sua cachola contra eles, com os diabos, Devagar. Calvo ele era e milionário, maestro di dolor che sanno. Limite do diáfano em. Porquê em? Diáfano, adiáfano. Se se pode por os cinco dedos através, é porque é uma grade, se não uma porta. Fecha os olhos e vê." (2000b, p. 52)] 
tual, à pura animação pelo Geist" (DERRIDA, 1994, 43), ou seja, impede uma interpretação, na ideia de uma busca do sentido, e exige do leitor os murmúrios da gestualidade do Geist. Ora, não se escapa, principalmente em um texto literário, da linguagem e de suas enunciações, mas a tentativa desse diáfano - disso que se faz através da luminosidade - é tornar o impalpável em não-impalpável - adiáfano - no sentido de tornar a presença, inicialmente, uma ausência e dessa ausência compreender a materialidade. As assinaturas de Stephen, como todas as marcas dos personagens de Ulysses, não são manifestações fenomenológicas do próprio, destinado da linguagem, que se desdobram por uma apresentação do si próprio. O que Stephen procura como assinatura não é seu próprio nome estampado na lombada do "grande épico por ser escrito" sobre a Irlanda, mas as "signatures of all things I am here to read". Ele dispõe-se a ler as coisas, pela visualidade, pela "faneidade" dos instrumentos. O problema retorna não sobre o sujeito - como se pode suspeitar num monólogo mas sobre a imagem que dele pode se fazer, pela leitura que, de certa forma, exclui um querer-dizer por um ouvir-dizer; de uma afirmação que se pode apenas interpretar por uma afirmação ativa dos desejos, manifestos na leitura das coisas - da concretude snotgreen ou oinopa ponton mesclada.

O monólogo, desse modo, pode ser repensado enquanto representação da palavra, como imagem de palavra. Não mais uma autoimplicação do si em seu imo, mas uma relação com o outro. Esse outro não presente é a marca de sua impureza significativa, ou seja, de sua escritura destituindo-se do aspecto. Se o monólogo interior faz com que sintamos como ausência o diálogo e, portanto, toda possibilidade de alteridade, ao mesmo tempo podemos nos conduzir por uma compreensão dessa ausência como natureza própria da linguagem, fazendo-se para além de uma mera física da voz e do sentido, ou como propõe Derrida em sua leitura de Husserl: “a (...) vantagem dessa redução ao monólogo interior é que a ocorrência física da linguagem parece realmente ausente" (1994, p. 50). Tomando-se esse princípio, a técnica joyciana vincula-se a perda do signo como remissão do sentido para si mesmo no interior de sua vida íntima ou ainda de sua "fala na solidão". Assim, o que está presente no monólogo não é a realidade trazida pelas palavras, mas a própria palavra concebida como representação neutra de uma perda de realidade. A inexistência da palavra monologada se apresenta como impossibilidade de transpor à realidade seu aspecto de realidade, em outras palavras, o signo que representa uma ausência é impossível ganhar concretude para além da linguagem auto-implicada. A semiótica de auto-implicação proposta por Foucault, em "Linguagem e literatura", ou quarta semiologia, é de certo modo um mecanismo importante para se compreender a designação do monólogo como força sobre si mesmo, como repetição da "linguagem pela linguagem". Diz o filósofo: "para saber como a literatura se significa, seria preciso saber como ela é significada, onde ela se situa no mundo dos 
signos de uma sociedade" (FOUCAULT, 2001, p. 163). Nesse sentido, a necessidade de uma figura, que seja o monólogo, para compreender esse signo social faz com que compreendamos o outro implicado no interior dessa linguagem manifesta. Há aqui, sem dúvida, um sentido de duração que permite conduzir-se pela aparição diáfana dos sons e dos grafemas. Como a obra é significada se ela não é significada? Seria uma primeira pergunta, necessária. Mas se o outro, para quem Stephen fala, é aquele que lê os aspectos ainda não verbais da linguagem aí temos uma ação afirmativa da implicação da obra no universo imaginário de uma tradição, que seja joyciana, ou dito de outro modo, a leitura de palavras que ainda não existem e que precisam ser lidas, mesmo na inexistência.

Stephen abre o seu monólogo com um "pensar através dos meus olhos". É o olhar que diz um sim. Não a palavra sim, intensamente interpretada por Derrida, mas um só gesto desse eu que está here to read. Para fora de toda possibilidade íntima da designação, o olhar está fora de todo traço ao mesmo tempo em que é o único rastro desse pensamento silencioso do monólogo. A escritura é mais ainda silêncio pelo stream of consciousness e por assim dizer por sua antidiscursividade. Em seguida, hamletianamente, diz "My soul walks with me, form of forms. So in the moon's midwatches I pace the path above the rocks, in sable silvered, hearing Elsinore's tempting flood." (JOYCE, 2000a, p. 55) Eis a forma de um outro tempo, um aspecto novo ao artífice. Esse eterno pensador de labirintos - na "enchente tentadora" do mítico castelo - faz de si técnica de si. Seu olhar agora é tornado som que prenuncia a fatídica torre do príncipe da Dinamarca. Como dizer assim o que ouço-dizer? A palavra joyciana é visível e audível. A forma do monólogo carrega o afeto para uma visão outra da realidade, uma sombra de impenetrabilidade, da qual se espera um sim. Silencio. Esse caminho rochoso é de certo modo apenas o possivelmente audível (hearing Elsinore's), uma vez que aquilo que se pode ver no monólogo é nada ou apenas tentação.

O Stimmung da produção lírica em certo sentido rege a construção dessa audição. As imagens são incorporadas à linguagem justamente por estarem fraturadas pelo silêncio que as mesmas portam pelo monólogo. Essa disposição anímica do estado lírico de Stephen, por exemplo, dilui a consistência de todo estado naturalista da imagem, ou seja, vale mais o tempo do inconsciente, a disposição - a afinação - do eu no outro, sua fusão de ambiente e "espírito" do que propriamente uma construção da lógica da língua. A confusão babélica de Ulysses pode ser pensada, com

2 [BSP: "Minha alma caminha comigo, forma das formas. Assim sob as meias-vigílias da lua eu ando a passos largos pelo caminho acima das rochas, de areia prateada, ouvindo a torrente tentadora de Elsinore" (2005, p. 52)]

[AH: "Minha alma caminha comigo, forma das formas. Assim aos meios quartos da lua palmilho o trilho acima das rochas, em areia prateada, Ouvindo a maré aliciante de Elsinore." (2000b, p. 62)] 
isso, como uma forma do poetizar lírico que intenta romper, ou quaseromper, o código pela fusão do pensado e do falado, de dois atos de linguagem. Em Conceitos fundamentais da poética, Emil Staiger propõe que o "poetizar lírico é aquele em si impossível falar da alma, que não quer ser tomado pela palavra, no qual a própria língua já se envergonha de sua realidade rígida, e prefere furtar-se a todo intento lógico e gramatical" (1993, p. 72). Desse modo, a disposição (Stimmung) segue em dois caminhos: a afinação e a ambientação. É no ritmo do monólogo que se pode compreender o ofuscamento dessa disposição do sujeito em uma babel de tempos, de linguagens, de fraturas. $\mathrm{O}$ silêncio talvez seja o símbolo mais obscuro de Ulysses justamente porque a voz lírica se impõe como afinação da narrativa para fraturar a discursividade e imiscuir-se no próprio do sujeito no outro.

The voices blend and fuse in clouded silence: silence that is the infinite of space: and swiftly, silently the soul is wafted over regions of cycles of generations that have lived. A region where grey twilight ever descends, never falls on wide sagegreen pasturefields, shedding her dusk, scattering a perennial dew of stars. (JOYCE, 2000a, p. 541) ${ }^{3}$

As vozes em fusão, e o silêncio permeando tanto o canto em paralelo - a paródia a Thomas de Quincey - como a fugacidade do sujeito se convertendo em estado. Os objetos de linguagem são estados da linguagem nos quais o ofuscado rende um tempo a mais ao inconsciente, nessa ação detalhadamente semantizada pela estrutura onírica. Poderíamos, desse modo, pensar que a escritura joyciana em Ulysses é uma escritura de aspecto. A forma que se faz apenas aparência sem subjetividade. $\mathrm{O}$ aspecto indica o início de uma ação - essa da escritura no caso - que se molda no processo, no estado daquilo que há de mais interno à ação. Escrever o pensamento produz duração e desse modo os verbos de Ulysses precisariam de uma carga não modalizante, mas espacializante dos signos, da falência de seus signos. A ação é inação de um apenas através (os olhos ou o portão). A sincronicidade das recusas supõe uma operação na qual todo ato é pensamento, duração e não o julgamento acerca do ato. É nesse sentido que a escritura, advinda com a técnica do monólogo, é um sim - como o de Molly tantas vezes repetido. Ou como melhor propõe Derrida:

\footnotetext{
${ }^{3}$ [BSP: "As vozes se misturam e se fundem no silêncio nebuloso: silêncio que é o infinito do espaço: e rapidamente, silenciosamente a alma é transportada para regiões de ciclos de gerações que já viveram. Uma região sobre a qual sempre desce o crepúsculo cinza, que não cai nunca sobre as pastagens verde-amêndoa, deixando cair sua penumbra, espalhando um orvalho perene de estrelas" (2005, p. 454)]

[AH: "As vozes mesclam-se e fundem-se em nublado silêncio: silêncio que é o infinito do espaço: e célere, silente a alma é librada a regiões de ciclos e ciclos de gerações que viveram. Uma região onde crepúsculo cinza desce sempre, nunca pousa sobre amplos pastios salviverdes, vertendo seu fusco, esparzindo um perene sereno de estrelas.” (2000b, p. 534-535)]
} 
Tout événement produit par une marque performative, toute écriture aus sense large engage un oui, qu'il soit ou non phénoménalisé, c'est-àdire verbalisé ou adverbialisé comme tel. Molly dito ui, elle se rappelle oui, le oui qu'elle dit avec ses yeux pour demander oui avec ses yeux, etc. (DERRIDA, 1987, p. 126)

O sim (parônimo francês de ouï e de lui) é sempre uma marca "qu'il y a de l'adresse à l'autre" (DERRIDA, 1987, p. 127). Nesse sentido, a afirmação promete seu desejo de memória justamente no sentido que está performando-se para um outro que entende a circunstância dos olhos e dos ouvidos - do visível do pensamento de Stephen e dos sons de concha ao caminhar pela praia. A matéria da linguagem é uma forma de acabar e retorquir com uma leitura meramente legitima da crítica. O texto de Ulysses afirma que é necessário o leitor contrassinar palavra a palavra esse sim monologante de seus personagens. A escritura, nesse caso sendo aspecto, faz de si uma duração de matizes, de tons do dizer que destronam o narrador e fazem, com isso, surgir uma vocalidade escrita que primeiramente desestabiliza a linguagem enquanto existência fenomênica (por uma espécie de substituição ao silêncio); e ainda reconduz o pensamento como linguagem na duração do escrito, que foge (pois grafa) a um tempo da presença do sujeito. Os olhos aqui são de temer, pois são também os ouvidos de um gesto de afirmação, de um alhures para as marcas da escritura no tempo (im)perfectivo do discurso.

O que temer em Joyce? Por que temer Ulysses? TeMER o tempo. Temporalizar o temor. Estouvar a reflexão e construir-se como temerário. Esse texto é antes de tudo uma profanação, pura temeridade. Não no sentido banal e risível da negatividade, mas como uma possibilidade de na falta, na recusa conduzir-se para além do mero sublime da consciência, ou seja, na audácia inconsiderada do tempo no inconsciente - no stream of consciousness - compreender a própria dinâmica do temor, da transitoriedade desse dia enlutado, para além de todo o saber precoce e preconizante. Joyce nos propõe estouvamentos - dedálicos e bloomeos - para, de certa forma, macular nossa assinatura do ouvir, do ver. A desconfiança de Stephen acerca da "aquacidade do pensamento e da linguagem" é uma espécie de método para desmontar todo método, de caminho tortuoso para destronar a necessidade de um caminho. É como voz da distância que Joyce propôs Ulysses e assim permanece. Quanto mais maculados estivermos, mais a imaginação da matéria terá a fluidez da linguagem. Temeridade é despropósito apenas se não se leva a sério a possibilidade do riso, da paródia; temeridade é temporalização profana que faz contornar as torres - seja a Martello seja Elsinore - para ler no entorno aquilo que torna a ser promessa e afirmação. O desatino necessário da gravação - do gramophone - no sentido de que toda assinatura, como afirma Derrida, "est toujours (...) le performatif synthétique d'une promesse et d'une mémoire 
qui conditionne tout engagement" (1987, p. 94-95). A babel e a assinatura, a escritura e o movimento da diferença detonam des tours.

Piero Eyben pieroeyben@gmail.com Universidade de Brasília

\section{Referências Bibliográficas}

AUERBACH, Erich. Mímesis. 4. ed. São Paulo: Perspectiva, 1998.

BATAILLE, Georges. L'expérience intérieure. Paris: Gallimard, 2009.

BLANCHOT, Maurice. Conversa infinita: a palavra plural. São Paulo: Escuta, 2001, v. 1.

DELEUZE, Gilles; GUATTARI, Félix. Milles Plateaux: Capitalisme et Schizophrénie 2. Paris: Minuit, 1980.

DERRIDA, Jacques. L'écriture et la différence. Paris: Seuil, 1967. . Ulysse gramophone: Deux mots pour Joyce. Paris: Galilée, 1987.

. A voz e o fenômeno: introdução ao problema do signo na fenomenologia de Husserl. Rio de Janeiro: Jorge Zahar, 1994.

. Salvo o nome. Campinas: Papirus, 1995a.

. Paixões. Campinas: Papirus, 1995b.

FOUCAULT, Michael. Linguagem e literatura. In: MACHADO, Roberto. Foucault: a filosofia e a literatura. 2. ed. Rio de Janeiro: Jorge Zahar, 2001. 
FREUD, Sigmund. Introducción del narcisismo [1914]. In: Obras completas: contribución a la historia del movimiento psicoanalítico; Trabajos sobre metapsicología y otras obras: 1914-1916. 2. ed. Buenos Aires: Amorrortu, 2007, v. XIV, p. 65-98.

JOYCE, James. Ulysses. Annotated Students Edition. New York: Peguin, 2000a.

. Ulisses. 12. ed. Trad. Antonio Houaiss. Rio de Janeiro: Civilização Brasileira, 2000b.

. Ulisses. Trad. Bernardina da Silveira Pinheiro. Rio de Janeiro: Objetiva, 2005.

MALLARMÉ, Stéphane. Divagations. In: Oeuvres complètes II. Texte établi et annoté par Bertrand Marchal. Paris: Gallimard/Pléiade, 2003.

STAIGER, Emil. Conceitos fundamentais da poética. 2. ed. Rio de Janeiro: Tempo Brasileiro, 1993. 